\title{
BMJ Open Incidence and risk factors for falls among community-dwelling elderly subjects on a 1-year follow-up: a prospective cohort study from Ernakulam, Kerala, India
}

\author{
Divyamol K Sasidharan (D) ,1,2 Priya Vijayakumar, ${ }^{3}$ Manu Raj, ${ }^{4}$ Sumi Soman, ${ }^{5}$ \\ Libin Antony, ${ }^{5}$ Abish Sudhakar, ${ }^{6}$ Conrad Kabali ${ }^{7}$
}

To cite: Sasidharan DK, Vijayakumar P, Raj M, et al. Incidence and risk factors for falls among communitydwelling elderly subjects on a 1-year follow-up: a prospective cohort study from Ernakulam, Kerala, India. BMJ Open 2020;10:e033691. doi:10.1136/ bmjopen-2019-033691

- Prepublication history for this paper is available online. To view these files, please visit the journal online (http://dx.doi. org/10.1136/bmjopen-2019033691).

Received 02 September 2019 Revised 13 May 2020

Accepted 04 June 2020

Check for updates

(C) Author(s) (or their employer(s)) 2020. Re-use permitted under CC BY-NC. No commercial re-use. See rights and permissions. Published by BMJ.

For numbered affiliations see end of article.

Correspondence to Professor Priya Vijayakumar; divz64@gmail.com

\section{ABSTRACT}

Objectives There is limited knowledge regarding epidemiology and risk of falls among the elderly living in low-income and middle-income countries. In this situation, the current study aims to report the incidence of falls and associated risk factors among free living elderly population from Kerala, India.

Design Prospective cohort study with stratified random cluster sampling.

Setting The study location was Ernakulam, Kerala, India, and we collected information via house visits using a questionnaire. During the research, the subjects were followed up prospectively for 1 year by phone at intervals of 3 months and missing subjects were contacted by house visits.

Participants Community-dwelling elderly above 65 years of age.

Results We recruited a total of 1000 participants out of which a total of $201(20.1 \%)$ subjects reported a fall during the follow-up. The incidence rate of falls was 31 (95\% Cl 27.7 to 34.6) per 100 person-years. Female sex (OR 1.48, 95\% Cl 1.05 to 2.10, $\mathrm{p}=0.027$ ), movement disorders including Parkinsonism (OR 2.26, 95\% Cl 1.00 to $5.05, \mathrm{p}=0.048)$, arthritis (OR $1.48,95 \% \mathrm{Cl} 1.05$ to $2.09, p=0.026)$, dependence in basic activities of daily living (OR, 3.49, 95\% $\mathrm{Cl} 2.00$ to $6.09, \mathrm{p}<0.001)$, not using antihypertensive medications $(0 \mathrm{R}, 1.53,95 \% \mathrm{Cl} 1.10$ to $2.13, p=0.012$ ), living alone during daytime (OR 3.27 , $95 \% \mathrm{Cl} 1.59$ to $6.71, \mathrm{p}=0.001$ ) and a history of falls in the previous year (OR, $2.25,95 \% \mathrm{Cl} 1.60$ to $3.15, \mathrm{p}<0.001$ ) predicted a fall in the following year.

Conclusions One in five community-dwelling senior citizen fall annually and one in four who fall are prone to fall again in the following year. Interventions targeting falls among the elderly need to focus on modifiable risk factors such as living alone during daytime, movement disorders, arthritis and dependence on basic activities of daily living.

\section{INTRODUCTION}

Globally, there are an estimated 962 million people aged 60 or over, comprising $13 \%$ of the total population. ${ }^{1}$ In this segment of
Strengths and limitations of this study

- The study has a prospective cohort study design with a large sample size $(n=1000)$.

- The study population represented both urban and rural population from different socioeconomic scale levels.

- None of the participants were lost to follow-up and a fall diary was used to avoid recall bias.

The data are from a single study setting.

The study has a short period of follow-up (1 year).

the population, unintentional injuries are reported to be the fifth-leading cause of death globally and falls constitute two out of every three deaths in this category. ${ }^{2} \mathrm{~A}$ fall is defined by The Kellogg International Working Group as 'unintentionally coming to the ground or some lower level and other than as a consequence of sustaining a violent blow, loss of consciousness, sudden onset of paralysis as in stroke or an epileptic seizure'. ${ }^{3}$

The incidence of falls and the consequences of falls have been higher in lower-income and middle-income countries as compared with high-income countries $^{4-6}$ mainly because fall preventing interventions are not that freely available in many parts of these countries. ${ }^{7}$ Each year an estimated 646000 individuals die from falls globally of which over $80 \%$ are in low-income and middle-income countries. ${ }^{4}$ In 2010, for example, years lived with disability (YLDs) due to reported falls were 631.2 per 100000 (population) in India and 674.4 per 100000 in China, compared with 472.2 per 100000 in the USA. ${ }^{5}$ In that year, the global share of YLDs due to falls in adults aged 50-59 years was $66 \%$ in lowincome and middle-income countries and $34 \%$ in high-income developed countries. ${ }^{6}$ 
Clearly,the situation needs to be addressed urgently as already over $70 \%$ of the world's older population live in low-income and middle-income and the proportion is likely to increase in the coming decades due to increasing longevity in all the regions of the world. ${ }^{8}$

Many prospective population-based studies have examined the epidemiology of falls in the community-dwelling elderly across different settings. The reported incidence rates show wide variability from as low as $29 \%$ to as high as $40 \%$ in this population..$^{9-14}$ Furthermore, various studies done in India too have reported the prevalence of falls in community-dwelling elderly ranging from $13 \%$ to $53 \% .^{15-18}$ The incidence of recurrent falls (more than two episodes per calendar year was reported to be $11 \%-21 \%$ by Lord et a $\varphi^{9}$

The risk factors for falls in the elderly as reported by Lord $e t a t^{\ominus}$ can be grouped into seven major categories: sociodemographic factors, balance and mobility factors, sensory and neuromuscular factors, psychological factors, medical factors, medication use and environmental factors. ${ }^{9}$ A recent meta-analysis by Deandrea $e t ~ a l^{19}$ pooled data from 74 prospective cohort studies that reported risk factors for prospective falls among community-dwelling elders. A prior history of falls, gait problems, walking aid use, vertigo, Parkinson's disease and antiepileptic drug use were the dominant reasons for prospective falls in this age group. ${ }^{19}$

The primary objective of our study was to report the incidence of falls in community-dwelling elderly population from Ernakulam, Kerala, India through a year-long prospective follow-up schedule, and the secondary objective was to identify factors that can predict a risk for future falls in community-dwelling elderly.

\section{METHODS}

\section{Selection and description of participants}

Design and setting

The current study is a community-based prospective cohort study that was conducted in an area within a radius of $10 \mathrm{~km}$ from the study centre (Amrita Institute of Medical Sciences and Research Centre, Kochi, Kerala). The study was conducted over a period of 3 years (November 2014 to November 2017). This circular area included 12 panchayats, 4 municipalities and 1 corporation. The study area comes under Ernakulam district of Kerala, South India.

We calculated the sample size using a previously published study by Mitchell-Fearon et al which reported $21.7 \%$ prevalence for falls in the elderly. ${ }^{20}$ We selected an alpha of 0.05 and an allowable error of $20 \%$ giving us a minimum sample size of 347 subjects. The design effect for the sampling method (multistage stratified random cluster sampling) was calculated using a pilot of 10 clusters (cluster size $\mathrm{k}=25$ ) that provided an intraclass correlation of 0.023 . The sample size adjusted for design effect was 539 (inflation factor of 1.552). We enrolled a total of
1000 participants anticipating significant subgroup differences within the study sample.

\section{Participants}

We used stratified random cluster sampling method to select the participants. The sample was stratified at two levels, rural urban (level 1) and at the level of individual local self-governing units (LSGs, level 2). A total of 40 clusters using probability proportional to size technique were selected randomly from the list of all available clusters within the defined geographical area. Each cluster was from an individual electoral ward within the LSGs. We selected 25 participants from each cluster. In each cluster, a random starting point was selected and households were visited in a sequential manner by the principal investigator (PI) and staff till 25 subjects were recruited. A flow chart on the study design used in the present study is shown in figure 1. The inclusion criteria were: (1) minimum age of 65 years or more (2) ambulant physical status (3) intention to stay in the study area for a minimum of 1 year after assessment and (4) ability to communicate in English/Malayalam language. The exclusion criteria included complete dependence for day-to-day activities.

\section{Operational definitions}

A fall was defined as suggested by The Kellogg International Working Group as mentioned in the introduction. ${ }^{3}$

A recurrent fall was defined as falling of two or more times during the follow-up period of 1 year. ${ }^{9}$

\section{Patient and public involvement}

Patients and the public were not specifically involved in the planning and execution of this study. However, they were informed of the need of the study and quarterly follow-up which was to be done telephonically.

\section{Technical information}

A study questionnaire was prepared after a detailed review of the literature on studies related to falls in the elderly; however, the questionnaire was freshly prepared by us and not derived from other studies. The study questionnaire included questions relating to the sociodemographic profile, comorbidities, physical activity, medication use and environmental assessment. This questionnaire was initially piloted over a small number of patients $(n=50)$ and the redundant questions were either removed or modified. The modified questionnaire was reviewed by subject experts and was approved for use in the full study.

All initial assessments were done at the participant's home. The research team (PI, two nurses) visited all the recruited subjects at their home premises. The study questionnaire was administered by the PI by means of a face-to-face interview during house visits. In addition, height, weight and blood pressure readings were taken by the trained staff (nurses) that accompanied the PI. All subjects were advised to keep a fall diary in which they were instructed to note down any incident of fall along with the date and time of the fall, what the patient was doing when he fell, what caused the fall, whether it was a 


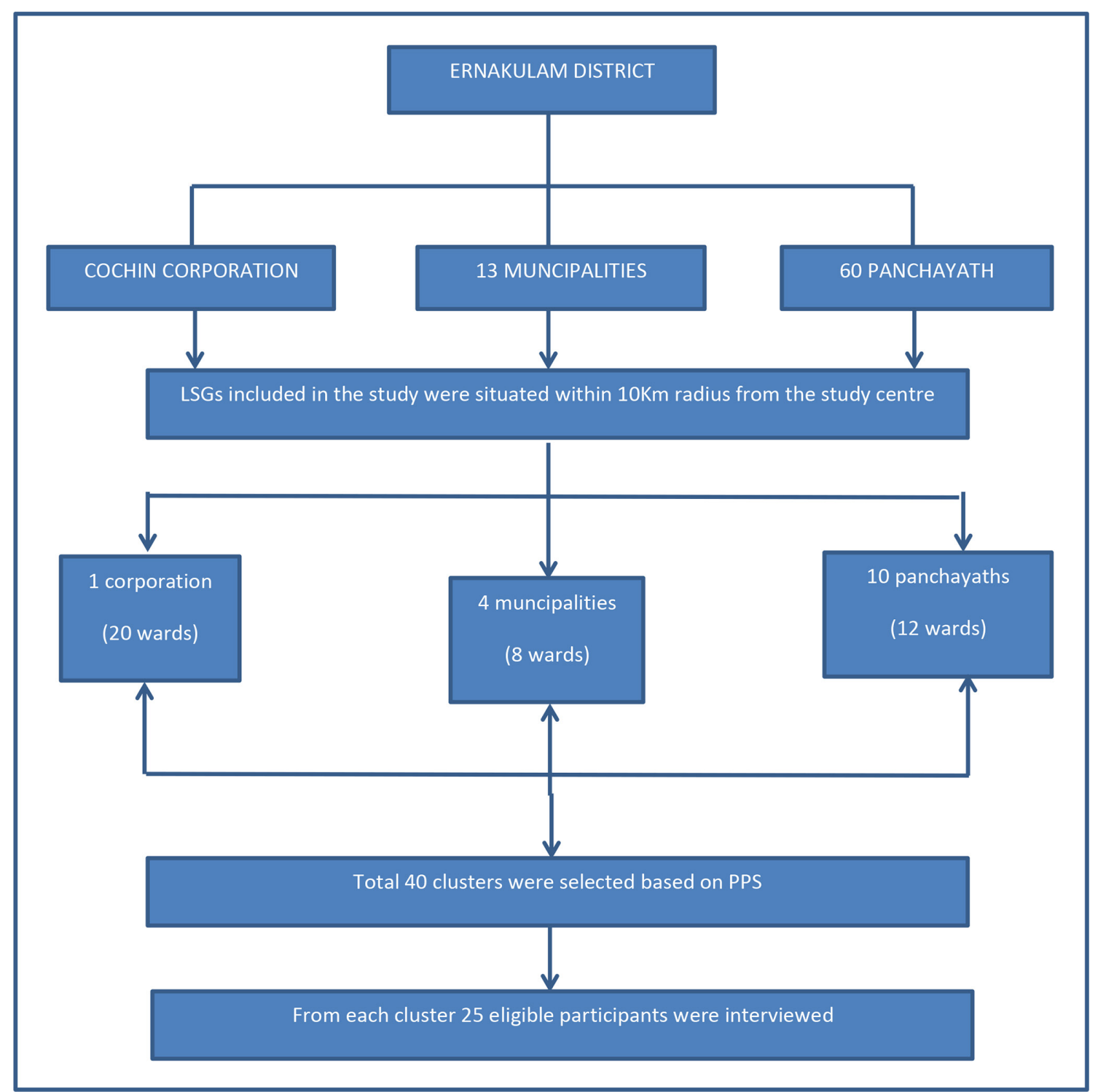

Figure 1 Flow chart of the study design. LSG, local self-governing unit.

witnessed fall or not and whether the fall had any consequences or complications. A 3 monthly follow-up was done by telephonic conversation with the enrolled subjects for 1 year from the first visit. Those who were not available over the phone were contacted via house visits by the research staff and hence no missing data were encountered in the study. In addition, the fall diaries of those who reported a fall from the same cluster were reviewed during these house visits. The data collection period were from August 2015 to April 2017.

\section{Statistics}

We summarised demographic and socio-economic variables to characterise the study population (table 1). We presented the mean and SD for normally distributed continuous variables. All categorical variables are expressed in number and percentages. We used $\mathrm{X}^{2}$ test to examine the association of categorical risk factors with prospective falls. All individual factors with a $\mathrm{p}<0.2$ for association on bivariate analysis were selected for multivariate analysis. Multiple binary logistic regression was used to construct the prediction model for prospective falls. We selected Logistic regression after verifying lack of overdispersion using the Pearson and deviance methods. The cut-off point for statistical significance was set at an $\alpha$-level of $5 \%$. We reported the adjusted ORs (aOR) with 95\% CIs. We encountered no missing data in the study. Statistical analysis was done using IBM SPSS Statistics V.20 Windows (SPSS).

We collected written informed consent from the consenting subjects before recruitment to the study and the same was documented for future reference. The consent contained the title, purpose, methods employed in the study, benefits to the subject as well as to their families. It was also made clear that participation in this research is purely voluntary. The confidentiality of the study during the analysis was also mentioned in the consent. 


\begin{tabular}{|c|c|}
\hline Demographic factors & $\mathbf{N}(\%)$ \\
\hline \multicolumn{2}{|l|}{ Gender } \\
\hline Male & $432(43.2)$ \\
\hline Female & $568(56.8)$ \\
\hline \multicolumn{2}{|l|}{ Age group } \\
\hline $65-75$ & $648(64.8)$ \\
\hline $75-85$ & $262(26.2)$ \\
\hline$>85$ & $90(9.0)$ \\
\hline \multicolumn{2}{|l|}{ Weight Status (BMI) } \\
\hline Underweight $(<18.5)$ & $124(12.4)$ \\
\hline Normal (18.5-22.9) & $340(34.0)$ \\
\hline Overweight (23-24.9) & $188(18.8)$ \\
\hline Preobese (25-29.9) & $264(26.4)$ \\
\hline Obese $(>30)$ & $84(8.4)$ \\
\hline \multicolumn{2}{|l|}{ Education } \\
\hline Graduate and above & $132(13.2)$ \\
\hline Diploma/pre-=degree & $85(8.5)$ \\
\hline Middle class/primary & $657(65.7)$ \\
\hline Illiterate & $126(12.6)$ \\
\hline \multicolumn{2}{|l|}{ House hold } \\
\hline Living with family/caretaker & $820(82.0)$ \\
\hline Living alone during daytime & $145(14.5)$ \\
\hline Living alone & $35(3.5)$ \\
\hline \multicolumn{2}{|l|}{ Domicile } \\
\hline Urban & $700(70.0)$ \\
\hline Rural & $300(30.0)$ \\
\hline
\end{tabular}

BMI, body mass index.

\section{RESULTS}

\section{Baseline characteristics of the study population}

We recruited a total of 1000 participants from 40 individual predesignated clusters spread across a circular geographical area with the study institution as the centre point. The distribution of gender, age categories, weight status, education level, household living pattern and area of domicile are presented in table 1 . The mean age of the study subjects was 72.7 (7.2) years. Among the study participants, $568(56.8 \%)$ were female, $87.4 \%$ were literate and $82 \%$ lived with family or caretakers. A total of $348(34.8 \%)$ were either preobese or obese as per Asian Criteria of BMI classification. ${ }^{21}$ The morbidity profile of the study population was published earlier. ${ }^{22}$ The selfreported prevalence of diabetes mellitus, coronary artery diseases and cerebrovascular accidents were $34.2 \%$, $20.1 \%$ and $5.3 \%$, respectively. Among the study subjects, $768(76.8 \%)$ were hypertensive as documented either by high values on house visit measurement or by current treatment for hypertension. Among hypertensives, a total of 528 subjects $(68.8 \%)$ reported taking treatment for hypertension and remaining $240(31.2 \%)$ were newly detected during the baseline evaluation of the study.

\section{Incidence of falls in the study population}

A total of $201(20.1 \%)$ subjects reported a fall during the prospective follow-up period of 1 year. The total fall episodes during the follow-up period were 301. The overall incidence rate of falls was $31(95 \%$ CI 27.7 to 34.6) per 100 person-years. The corresponding figures for elderly men and women separately were $21.2(95 \%$ CI 18.5 to 24.2 ) and 38.3 (95\% CI 34.6 to 42.3 ), respectively. The stratified incidence rates for age groups $65-75,75-85$ and more than 85 were $27.4,36.8$ and 41.1 per 100 person-years, respectively. Among the participants, more women reported a fall compared with men $(23.6 \% \mathrm{v} / \mathrm{s} 15.5 \%, \mathrm{p}, 0.002)$. In the age-stratified groups, $27(30.0 \%)$ subjects in the age group $>85$ years reported a fall in the follow-up period, compared with $54(20.6 \%)$ in the age group $75-85$ years and 120 $(18.5 \%)$ in the $65-75$ years group. (p 0.038). In addition, $53(5.3 \%)$ people sustained recurrent falls (two or more falls) during the follow-up.

\section{Factors associated with prospective falls}

The association of baseline factors with a prospective history of falls during the follow-up period is presented in table 2 as unadjusted bivariate comparisons. Among all baseline variables, only gender and living arrangement showed a significant association with a prospective history of falls on bivariate comparisons. Females had a higher risk of fall when compared with males (OR 1.68, $95 \%$ CI 1.21 to 2.33, p 0.002). Those living alone during daytime also had a higher risk of falls when compared with those living with family/caretaker (OR 2.95, 95\% CI 1.47 to $5.94, \mathrm{p}=0.002)$. The association of prospective falls with factors affecting locomotion was explored by bivariate analysis and is presented in table 3. Among the factors affecting locomotion, only parkinsonism (OR 2.66, 95\% CI 1.23 to 5.78, $\mathrm{p}=0.010$ ), vertigo (OR $1.51,95 \%$ CI 1.10 to 2.06. $\mathrm{p}=0.010$ ), arthritis (OR 1.62, $95 \%$ CI 1.17 to $2.25, \mathrm{p}=0.004)$, numbness and paraesthesia of feet (OR 1.37, 95\% CI 1.00 to $1.86, \mathrm{p}=0.048$ ) dependence in basic activities of daily living (BADL) (OR 3.45, 95\% CI 2.01 to 5.92, $\mathrm{p}<0.001$ ) and dependence in instrumental activities of daily living (OR 1.63, $95 \%$ CI 1.18 to $2.25, \mathrm{p}=0.003$ ) showed significant associations with prospective falls on bivariate comparisons. A history of falls in the preceding year also had a higher risk for prospective falls (OR 2.59, 95\% CI 1.87 to 3.58, $\mathrm{p}<0.001)$.

Furthermore, among baseline factors only gender showed an association with recurrent falls on bivariate comparisons (OR 2.44, 95\% CI 1.29 to 4.63. p 0.005). Among factors affecting locomotion, dependence in BADL (OR 5.00, 95\% CI 2.38 to 10.10. p $<0.001$ ), dependence in instrumental activities of daily living (OR 1.79, $95 \%$ CI 1.03 to 3.12. $p=0.038$ ) and a history of falls in the preceding year (OR 4.20, 95\% CI 2.38 to $7.39 \mathrm{p}<0.001$ ) 
Table 2 Association of falls with baseline variables-bivariate comparisons

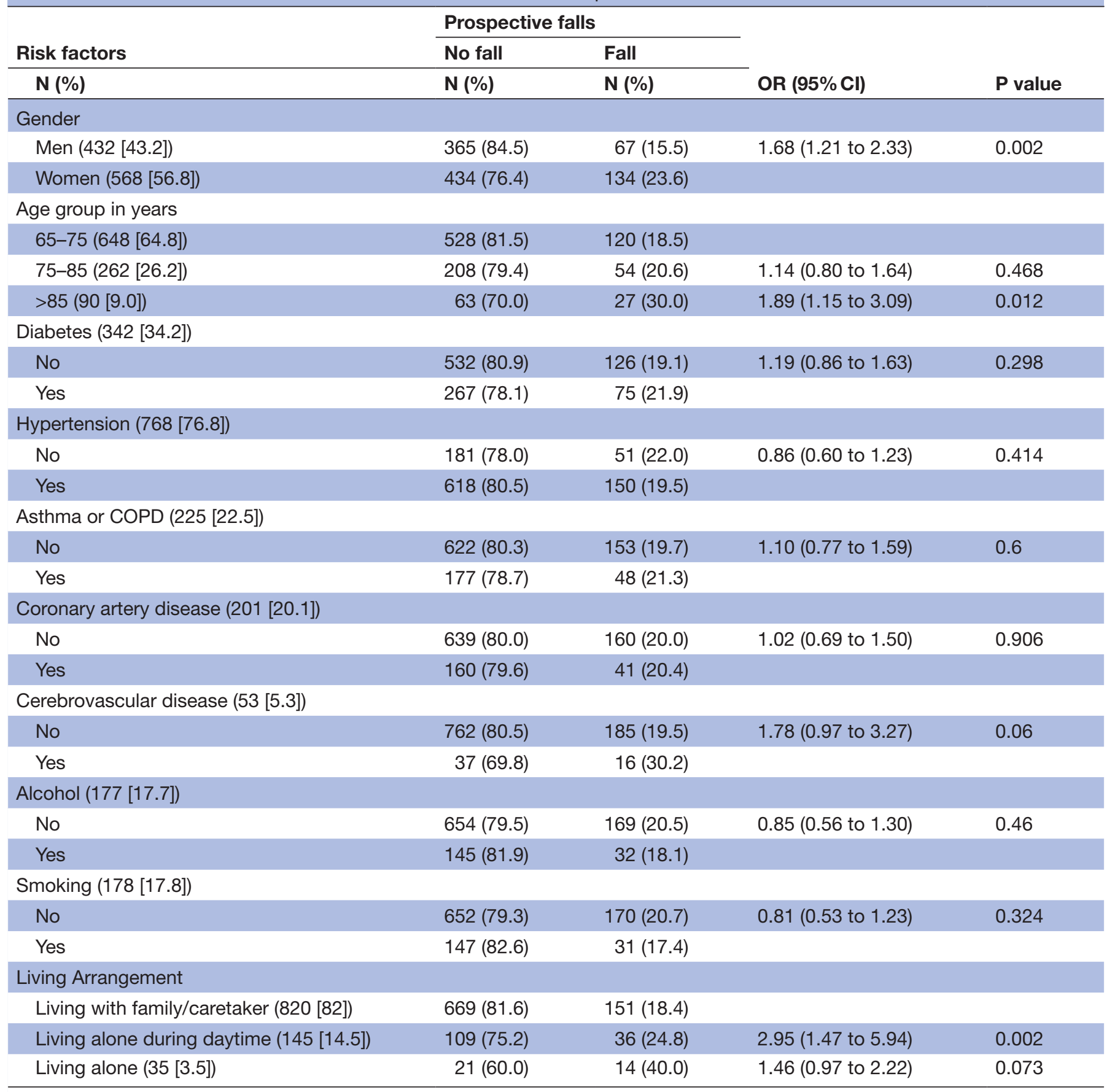

COPD, chronic obstructive pulmonary disease.

showed an association with recurrent falls on bivariate comparisons.

In the study population, $474(47.4 \%)$ subjects reported taking antihypertensives, $277(27.7 \%)$ reported taking antidiabetic medications and $69(6.9 \%)$ reported taking either benzodiazepines or other sedative drugs. There was no significant association for prospective falls with use of antihypertensive medications (OR $0.77,95 \%$ CI 0.57 to $1.06, \mathrm{p}=0.104$ ), antidiabetic medications (OR $1.14,95 \%$ CI 0.81 to $1.60, \mathrm{p}=0.446$ ) or benzodiazepines / sedatives (OR $1.56,95 \% \mathrm{CI} 0.90$ to $2.72, \mathrm{p}=0.110$ ) in bivariate comparisons.

\section{Independent risk factors for prospective falls}

The final adjusted model with independent predictors of prospective falls in the elderly is presented as table 4. The variables found to be significant $(\mathrm{p}<0.2)$ in bivariate analysis with falls were age, sex, living arrangement, vertigo, parkinsonism, arthritis, urinary symptoms, constipation, knee pain, paraesthesia of feet, history 
Table 3 Association of falls with factors affecting locomotion-bivariate comparisons

\begin{tabular}{|c|c|c|c|c|}
\hline \multirow[b]{3}{*}{ Risk factors } & \multicolumn{2}{|c|}{ Prospective falls } & \multirow[b]{3}{*}{ OR $(95 \% \mathrm{Cl})$} & \multirow[b]{3}{*}{$P$ value } \\
\hline & No fallers & Fallers & & \\
\hline & $\mathbf{N}(\%)$ & $\mathbf{N}(\%)$ & & \\
\hline \multicolumn{5}{|c|}{ Parkinsonism (28 [2.8]) } \\
\hline No & $782(80.5)$ & $190(19.5)$ & 2.663 (1.23 to 5.78$)$ & 0.01 \\
\hline Yes & $17(60.7)$ & $11(39.3)$ & & \\
\hline \multicolumn{5}{|c|}{ Vertigo (388 [38.8]) } \\
\hline No & $505(82.5)$ & $107(17.5)$ & 1.51 (1.10 to 2.06$)$ & 0.01 \\
\hline Yes & $294(75.8)$ & $94(24.2)$ & & \\
\hline \multicolumn{5}{|c|}{ Arthritis (281 [28.1]) } \\
\hline No & $591(82.2)$ & $128(17.8)$ & $1.62(1.17$ to 2.25$)$ & 0.004 \\
\hline Yes & $208(74.0)$ & $73(26.0)$ & & \\
\hline \multicolumn{5}{|c|}{ Knee pain (565 [56.5]) } \\
\hline No & $356(81.8)$ & $79(18.2)$ & 1.24 (0.91 to 1.70$)$ & 0.179 \\
\hline Yes & $443(78.4)$ & $122(21.6)$ & & \\
\hline \multicolumn{5}{|c|}{ Numbness and paraesthesia of feet (475 [47.5]) } \\
\hline No & $432(82.3)$ & $93(17.7)$ & $1.37(1.00$ to 1.86$)$ & 0.048 \\
\hline Yes & $367(77.3)$ & $108(22.7)$ & & \\
\hline \multicolumn{5}{|c|}{ Urinary symptoms (316 [31.6]) } \\
\hline No & $558(81.6)$ & $126(18.4)$ & $1.38(0.99$ to 1.90$)$ & 0.051 \\
\hline Yes & $241(76.3)$ & $75(23.7)$ & & \\
\hline \multicolumn{5}{|c|}{ Visual impairment (594 [59.4]) } \\
\hline No & $326(80.3)$ & $80(19.7)$ & $1.04(0.76$ to 1.43$)$ & 0.796 \\
\hline Yes & $473(79.6)$ & $121(20.4)$ & & \\
\hline \multicolumn{5}{|c|}{ Not independent in basic activities of daily living (59 [5.9]) } \\
\hline Yes & $766(81.4)$ & $175(18.6)$ & 3.45 (2.01 to 5.92$)$ & $<0.001$ \\
\hline No & $33(55.9)$ & $26(44.1)$ & & \\
\hline \multicolumn{5}{|c|}{ Not independent in Instrumental activities of daily living (306 [30.6]) } \\
\hline Yes & $572(82.4)$ & $122(17.6)$ & $1.63(1.18$ to 2.25$)$ & 0.003 \\
\hline No & $227(74.2)$ & $79(25.8)$ & & \\
\hline \multicolumn{5}{|c|}{ Regular exercise or yoga (342 [34.2]) } \\
\hline Yes & $281(82.2)$ & $61(17.8)$ & $1.25(0.89$ to 1.74$)$ & 0.198 \\
\hline No & $518(78.7)$ & $140(21.3)$ & & \\
\hline \multicolumn{5}{|c|}{ History of falls in the previous 1 year (269 [26.9]) } \\
\hline Yes & $182(67.7)$ & $87(32.3)$ & 2.59 (1.87 to 3.58$)$ & $<0.001$ \\
\hline No & $617(84.4)$ & $114(15.6)$ & & \\
\hline
\end{tabular}

of fall in the previous year, dependence in basic and instrumental activities of daily living, use of assistive devices for movement, cognitive impairment, depression, use of antihypertensive medications and benzodiazepines. The same were included in the final model construction. Among the factors examined in the logistic regression model, female sex (OR 1.48, 95\% CI 1.05 to $2.10, p=0.027$ ), parkinsonism (OR 2.26, $95 \% \mathrm{CI}$ 1.00 to $5.05, \mathrm{p}=0.048)$, arthritis (OR $1.48,95 \% \mathrm{CI} 1.05$ to 2.09, $\mathrm{p}=0.026$ ), dependence in BADL (OR 3.49, 95\% CI 2.00 to $6.09, \mathrm{p}<0.001)$, not using antihypertensive medications (OR 1.53, 95\% CI 1.10 to $2.13, \mathrm{p}=0.012$ ), living alone during the daytime (OR $3.27,95 \%$ CI 1.59 to $6.71, p=0.001$ ) and history of falls in the previous year (OR 2.59, 95\% CI 1.87, 3.58, $\mathrm{p}<0.001$ ) were found to be significantly associated with falls.

The factors included to assess the independent risk factors of recurrent falls were, female sex, vertigo, parkinsonism, arthritis and dependence in basic and instrumental activities of daily living and history of falls in the previous year. From the above, the independent predictors for recurrent falls were female sex (OR 2.05, 
Table 4 Adjusted model for risk factors of falls in community-dwelling elderly subjects $(n=1000)$

\begin{tabular}{|c|c|c|}
\hline Risk factors & Odds ratio $(95 \% \mathrm{CI})$ & P value \\
\hline \multicolumn{3}{|l|}{ All Falls } \\
\hline Females & 1.48 (1.05 to 2.10$)$ & 0.027 \\
\hline Arthritis & $1.48(1.05$ to 2.09$)$ & 0.026 \\
\hline Dependence in basic activities of daily living & $3.49(2.00$ to 6.09$)$ & $<0.001$ \\
\hline Living alone during daytime & 3.27 (1.59 to 6.71$)$ & 0.001 \\
\hline History of falls in the previous year & 2.25 (1.60 to 3.15$)$ & $<0.001$ \\
\hline \multicolumn{3}{|l|}{ Recurrent falls } \\
\hline Females & 2.05 (1.07 to 3.95$)$ & 0.031 \\
\hline Dependence in basic activities of daily living & $3.63(1.71$ to 7.70$)$ & 0.001 \\
\hline
\end{tabular}

95\% CI 1.07 to $3.95, \mathrm{p}=0.031)$, dependence in BADL (OR $3.63,95 \%$ CI 1.71 to $7.70, \mathrm{p}=0.001$ ) and history of falls in the previous year (OR $3.39,95 \%$ CI 1.89 to 6.05 , $\mathrm{p}<0.001)$.

\section{DISCUSSION}

The current study provides details of fall episodes experienced by free living elderly from Kerala, India during a prospective follow-up of 1 year. Approximately one in five elderly subjects in this age group reported a fall during the study period. There appears to be a sex-based difference in the proportion that fell with one in four elderly women falling compared with one in six men during the follow-up. The results also suggest a dose-response relationship between age and falls with more subjects falling in older age groups compared with relatively younger groups. In addition, every fourth person who fell reported one or more falls following the index fall episode during the study period.

The independent predictors for falls in the elderly included female sex, parkinsonism and related movement disorders, arthritis, dependence in BADL, not using antihypertensive medicines, living alone during daytime and a history of fall in the preceding year. The corresponding predictors for recurrent falls included female sex, dependence in BADL and a history of fall in the preceding year. To our knowledge, this is the only prospective cohort study done in India that focused on falls in free living elderly who were assessed in the community setting.

The incidence of falls in the elderly from our study appears to be at the lower end of the spectrum as reported by western studies $(29 \%-40 \%) \cdot{ }^{9-14}$ Interestingly, our results are more similar to that reported by a prospective study among community-dwelling elderly Chinese subjects. ${ }^{23}$ The incidence rate of falls in this study were 27.0, 32.4 and 22.0 per 100 person-years for all elderly, women and men, respectively. The proportion with recurrent falls in this study was also similar to our study $(4.75 \%$ vs $5.3 \%)$.

The risk factors for prospective falls in communitydwelling elderly was examined by a recent meta-analysis by Deandrea et al that pooled 74 prospective cohorts. ${ }^{19}$ Most of the prospective studies in the meta-analysis suggested that community-dwelling elderly women are at higher risk for falls compared with their male counterparts. The pooled estimates for falls (OR 1.30, 95\% CI 1.18 to 1.42) and recurrent falls (OR $1.34,95 \%$ CI 1.12 to 1.60 ) in this meta-analysis are in agreement with the current study.

Similar to the current study, several prospective studies have reported higher risk for falls among elderly patients with parkinsonism and/or related movement disorders similar to the current study. The meta-analysis suggested an aOR of 2.71 (95\% CI 1.08 to 6.84$)$ for falls and 2.84 (95\% CI, 1.77 to 4.58 ) for recurrent falls from five studies that looked for the same. Our study did not report any positive association between Parkinson's disease and recurrent falls, probably due to the small number of recurrent fallers $(5.3 \%)$ in the cohort.

Our finding of high risk for falls among those elderly with arthritis is in concordance with several other studies. $^{24-27}$ Together these studies suggest that the elderly with arthritis and/or chronic pain have a higher risk for falls. The The Global Longitudinal Study of Osteoporosis in Women(GLOW) cohort also reported a higher incidence of falls and fractures in postmenopausal women with osteoarthritis compared with osteoarthritis free peers. $^{27}$

Several studies have reported that living alone during the daytime is a risk factor for falls in the elderly as suggested by the current study. ${ }^{19}$ The meta-analysis is also in agreement with this observation (OR 1.33, 95\% CI 1.21 to 1.45 ) after looking at data from 11 studies that examined the same.

Reduced capability for BADL is also reported to be associated with falls in the elderly. ${ }^{28}$ Yokoya et al recently 
concluded that higher frequency of leaving home, higher exercise levels and presence of interest in activities (eg, meeting friends, shopping, working in the garden) were associated with a reduced risk for fall in communitydwelling elders. ${ }^{28}$ Therefore, maintaining and enhancing physical functions, principally walking ability and walking speed are critical for fall prevention among the elderly. ${ }^{29}$ Age appropriate exercises including those enhancing muscle strength and improving balance can probably reduce the incidence of falls among the elderly. ${ }^{30}$

A history of falls in the previous year appears to be the most consistent risk factor across several studies. ${ }^{19} 3031$ Pooled data from several studies in the recent meta-analysis puts the risk at an OR of 2.77 (95\% CI 2.37 to 3.25) for falls and an OR of 3.46 (95\% CI 2.85 to 4.22) for recurrent falls, in agreement with the current study (2.59 and 3.39, respectively) ${ }^{19}$ Suzuki reported that five out of six elderly with a history of falls were anxious about another fall and one in three said that they did not venture out again due to fear of another fall. ${ }^{30}$

One notable finding in our study was the lack of association for falls with medication use for most groups of medications except for antihypertensive medications. This is in contrast to a meta-analysis of the impact of medication classes on falls in elderly. ${ }^{32}$ Woolcott et al reported an OR of 1.41 (95\% CI 1.20 to 1.71) for falls among elderly with benzodiazepine use. ${ }^{32}$ The lack of association between sedatives use and falls in our study is probably due to the limited number of subjects reporting the use of the same $(6.9 \%)$. We saw an inverse association between falls and the use of antihypertensive drug use in the current study. One probable reason could be the high proportion of uncontrolled hypertensives in the study population. This finding needs to be explored further in future studies.

Several studies have earlier suggested that the prevalence of falls in low and middle income countries is higher than that reported from high-income countries. ${ }^{4-6}$ The morbidity from falls and related events too appear to be higher in low-income and middle-income countries compared with high-income countries like the USA. ${ }^{4-6}$ There appears to be low awareness about the consequences of falls in low-income and middle-income countries. This could probably be due to the lack of data regarding falls reported from these regions. It is expected that the awareness related to falls will improve with dissemination of data from the current study as well as similar studies from this region. The same may also stimulate research into the interventional options to reduce fall related mortality and morbidity. Interventional studies to prevent falls in the elderly are very relevant to the state of Kerala as it has the maximum proportion of elderly $(12.6 \%)$ in India as per 2011 census. ${ }^{33}$ This is much higher than the national average of $8.6 \%$, making Kerala more appropriate for future intervention studies in this area.

The strengths of the current study include the following: prospective cohort study design, large sample size $(n=1000)$, representative urban and rural population components, inclusion of participants from different socioeconomic levels, no participants lost to follow-up and use of a fall diary to avoid recall bias. However, the study included participants from a limited geographical setting and was able to follow up only for a short period (1 year), and hence the generalisation of the study findings is limited.

\section{CONCLUSION}

One in five community-dwelling elderly citizens fall on an annual basis and one in four of those who fall are prone to fall again in the same calendar year. Female sex, movement disorders including parkinsonism, arthritis, dependence in BADL, living alone during daytime and a history of falls in the previous year appear to predict a fall in the following year.

Any future intervention programme targeting a reduction in falls among the elderly in India should start in Kerala due to the high proportion of elderly in the state and extend to similar states later. Such studies should focus on the modifiable risk factors such as living alone at home during daytime, movement disorders and arthritis as identified by the current study. We need to encourage mechanisms that may reduce dependence of the elderly for BADL. Attention should also be given to encourage both physical and social activities among elderly subjects.

\author{
Author affiliations \\ ${ }^{1}$ Geriatric Medicine, Amrita Institute of Medical Sciences and Research Centre, \\ Cochin, Kerala, India \\ ${ }^{2}$ Geriatric Medicine, Government of Goa Directorate of Health Services, Panaji, Goa, \\ India \\ ${ }^{3}$ Geriatric Medicine, Amrita Vishwa Vidyapeetham, Kochi, Kerala, India \\ ${ }^{4}$ Pediatrics \& Pediatric Cardiology, Amrita Institute of Medical Sciences and \\ Research Centre, Cochin, Kerala, India \\ ${ }^{5}$ Public Health Research, Amrita Vishwa Vidyapeetham, Kochi, Kerala, India \\ ${ }^{6}$ Pediatric Cardiology, Amrita Institute of Medical Sciences and Research Centre, \\ Cochin, Kerala, India \\ ${ }^{7}$ Health Quality Ontario, Toronto, Ontario, Canada
}

Twitter Manu Raj @doc_manu

Acknowledgements We are thankful to Sunil K S, Ramya Raju, Georgina P and Jishnu S Lalu for the valuable inputs provided during planning, data collection and analysis stage.

Contributors DKS and PV conceptualised the original idea. DKS and MR did review of literature and planned, conducted analysed and prepared manuscript of the research work. PV supervised the experiment and in final editing of the article. SS and LA was involved in data acquisition and analysis. AS and CK derived the models and analysed the data.

Funding The authors have not declared a specific grant for this research from any funding agency in the public, commercial or not-for-profit sectors.

Competing interests None declared.

Patient consent for publication Not required.

Ethics approval The consent process and study protocol was approved by the Institutional Ethics Committee of Amrita Institute of Medical Sciences and Research centre. (Institutional Ethics Committee Registration Number: ECR/129/Inst/KL/2013).

Provenance and peer review Not commissioned; externally peer reviewed.

Data availability statement All data relevant to the study are included in the article or uploaded as online supplementary information.

Open access This is an open access article distributed in accordance with the Creative Commons Attribution Non Commercial (CC BY-NC 4.0) license, which 
permits others to distribute, remix, adapt, build upon this work non-commercially, and license their derivative works on different terms, provided the original work is properly cited, appropriate credit is given, any changes made indicated, and the use is non-commercial. See: http://creativecommons.org/licenses/by-nc/4.0/.

\section{ORCID iD}

Divyamol K Sasidharan http://orcid.org/0000-0002-0794-8000

\section{REFERENCES}

1 United Nations, Department of Economic and Social Affairs, Population Division. World Population Prospects: the 2017 Revision, Key Findings and Advance Tables. Working Paper No. ESA/P/ WP/248., n.d., 2017.

2 Rubenstein LZ. Falls in older people: epidemiology, risk factors and strategies for prevention. Age Ageing 2006;35 Suppl 2:ii37-41.

3 Gibson MJ, Andres RO, Isaacs B, et al. The prevention of falls in later life. A report of the Kellogg International Work Group on the prevention of falls by the elderly. Dan Med Bull 1987;34:1-24.

$4 \mathrm{WHO}$ fact sheet. Available: https://www.who.int/news-room/factsheets/detail/falls

5 Institute for Health Metrics and Evaluation: GBD Compare. Available: www.healthmetricsandevaluation.org/gbd [Accessed 25 May 2015].

6 Murray CJL, Vos T, Lozano R, et al. Disability-adjusted life years (DALYs) for 291 diseases and injuries in 21 regions, 1990-2010: a systematic analysis for the global burden of disease study 2010. The Lancet 2012;380:2197-223.

7 Peltzer K, Chatterji S, Hestekin H, et al. Measuring Prevalence and Risk Factors for Fall Related Injury in Older Adult in Low Middle Income Countries, Results from the WHO Study on Global AGEing and Adult Health 2013;6.

8 Beard JR, Biggs S, Bloom DE, et al. Global Population Ageing: Peril or Promise? Geneva: World Economic Forum, 2012: 148.

9 Lord SR, Sherrington C, Menz HB. Falls in Older People: Risk Factors and Strategies for Prevention. 2nd ed. Cambridge, MA: Cambridge University Press, 2007.

10 Tinetti ME, Speechley M, Ginter SF. Risk factors for falls among elderly persons living in the community. N Engl $J$ Med 1988;319:1701-7.

11 O'Loughlin JL, Robitaille Y, Boivin JF, et al. Incidence of and risk factors for falls and injurious falls among the community-dwelling elderly. Am J Epidemiol 1993;137:342-54.

12 Lord SR, Ward JA, Williams P, et al. An epidemiological study of falls in older community-dwelling women: the Randwick falls and fractures study. Aust J Public Health 1993;17:240-5.

13 Campbell AJ, Borrie MJ, Spears GF. Risk factors for falls in a community-based prospective study of people 70 years and older. $J$ Gerontol 1989;44:M112-7.

14 Luukinen H, Koski K, Laippala P, et al. Predictors for recurrent falls among the home-dwelling elderly. Scand J Prim Health Care 1995;13:294-9.
15 Sirohi A, Kaur R, Goswami AK, et al. A study of falls among elderly persons in a rural area of Haryana. Indian J Public Health 2017;61:99-104.

16 Krishnaswamy B, Usha G. Falls in older people national / regional review India, n.d. Available: http://www.who.int/ageing/projects/ SEARO.pdf

17 Saikia AM, Das AK, Saikia AM. Prevalence and correlates of falls among community-dwelling elderly of Guwahati City, Assam. Indian J Basic Appl Med Res 2016;5:185-90.

18 Sharma PK, Bunker $\mathrm{CH}$, Singh $\mathrm{T}$, et al. Burden and correlates of falls among rural elders of South India: mobility and independent living in elders study. Curr Gerontol Geriatr Res 2017;2017:1-8.

19 Deandrea S, Lucenteforte E, Bravi F, et al. Risk factors for falls in community-dwelling older people: a systematic review and metaanalysis. Epidemiology 2010;21:658-68.

20 Mitchell-Fearon K, James K, Waldron N, et al. Falls among community-dwelling older adults in Jamaica. SAGE Open 2014;4:215824401456435.

21 WHO Expert Consultation. Appropriate body-mass index for Asian populations and its implications for policy and intervention strategies. Lancet 2004;363:157-63.

22 Divyamol K, Sasidharan LJS, Vijayakumar P, et al. Morbidity pattern among the geriatric population in South India: an observational study. Epidemiol Int 2018;3:11-17.

23 Chu LW, Chi I, Chiu AYY. Incidence and predictors of falls in the Chinese elderly. Ann Acad Med Singapore 2005;34:60-72.

24 Leveille SG, Jones RN, Kiely DK, et al. Chronic musculoskeletal pain and the occurrence of falls in an older population. JAMA 2009;302:2214.

25 Doré AL, Golightly YM, Mercer VS, et al. Lower-Extremity osteoarthritis and the risk of falls in a community-based longitudinal study of adults with and without osteoarthritis. Arthritis Care Res 2015;67:633-9.

26 Hill KD, Williams SB, Chen J, et al. Balance and falls risk in women with lower limb osteoarthritis or rheumatoid arthritis. J Clin Gerontol Geriatr 2013;4:22-8.

27 Prieto-Alhambra D, Nogues X, Javaid MK, et al. An increased rate of falling leads to a rise in fracture risk in postmenopausal women with self-reported osteoarthritis: a prospective multinational cohort study (GLOW). Ann Rheum Dis 2013;72:911-7.

28 Yokoya T, Demura S, Sato S. Relationships between physical activity, ADL capability and fall risk in community-dwelling Japanese elderly population. Environ Health Prev Med 2007;12:25-32.

29 Maki BE. Selection of perturbation parameters for identification of the posture-control system. Med Biol Eng Comput 1986;24:561-8.

30 Suzuki T. [Epidemiology and implications of falling among the elderly]. Nihon Ronen Igakkai Zasshi 2003;40:85-94. Review. Article in Japanese.

31 Nevitt MC, Cummings SR, Kidd S, et al. Risk factors for recurrent nonsyncopal falls. A prospective study. JAMA 1989;261:2663-8.

32 Woolcott JC, Richardson KJ, Wiens MO, et al. Meta-analysis of the impact of 9 medication classes on falls in elderly persons. Arch Intern Med 2009;169:1952-60.

33 Census of India 2011, Chapter 2. Available: http://censusindia.gov.in/ vital_statistics/SRS_Report/9Chap\%202\%20-\%202011.pdf 